\title{
Trafficking abnormality and ER stress underlie functional deficiency of hearing impairment- associated connexin-31 mutants
}

\author{
Kun $\mathrm{Xia}^{1^{*}}$, Hong $\mathrm{Ma}^{2 *}$, Hui Xiong ${ }^{2 *}$, Qian Pan ${ }^{1}$, Liangqun Huang ${ }^{1}$, Danling Wang ${ }^{1}$, Zhuohua Zhang ${ }^{1,2} \bowtie$ \\ ${ }^{1}$ State Key Laboratory of Medical Genetics, Central South University, Changsha 410083, China \\ ${ }^{2}$ Burnham Institute for Medical Research, La Jolla, CA 92037, USA \\ \ Correspondence: zhangzhuohua@sklmg.edu.cn
}

Received September 26, 2010 Accepted October 9, 2010

\begin{abstract}
Hearing impairment (HI) affects $1 / 1000$ children and over $2 \%$ of the aged population. We have previously reported that mutations in the gene encoding gap junction protein connexin-31 (Cx31) are associated with HI. The pathological mechanism of the disease mutations remains unknown. Here, we show that expression of Cx31 in the mouse inner ear is developmentally regulated with a high level in adult inner hair cells and spiral ganglion neurons that are critical for the hearing process. In transfected cells, wild type $\mathrm{C} \times 31$ protein (Cx31wt) forms functional gap junction at cell-cell-contacts. In contrast, two HIassociated Cx31 mutants, Cx31R180X and Cx31E183K resided primarily in the ER and Golgi-like intracellular punctate structures, respectively, and failed to mediate lucifer yellow transfer. Expression of Cx31 mutants but not Cx31wt leads to upregulation of and increased association with the ER chaperone BiP indicating ER stress induction. Together, the $\mathrm{HI}$-associated $\mathrm{C} \times 31$ mutants are impaired in trafficking, promote ER stress, and hence lose the ability to assemble functional gap junctions. The study reveals a potential pathological mechanism of $\mathrm{HI}$-associated $\mathrm{C} \times 31$ mutations.
\end{abstract}

\section{KEYWORDS gap junction, bip, inner ear, protein folding}

\section{INTRODUCTION}

$\mathrm{HI}$ has dramatic effects on speech acquisition and literacy when it presents in early childhood and seriously compromises the quality of life in individuals affected at late onset.
Over 100 genes are associated $\mathrm{HI}$ in human with more than 30 being identified. Among these identified genes associated with $\mathrm{HI}$, several encode gap junction proteins (Petit et al., 2001).

Gap junctions, formed by hemichannels of the same or different connexins, mediate cell-cell communication by direct exchange of intracellular small molecules $(\leqslant 1 \mathrm{kDa})$ (Elfgang et al., 1995). Gene disruption studies in mice demonstrate essential roles of connexins in the development of various organs and in the maintenance of cellular homeostasis (Simon and Goodenough, 1998; Cohen-Salmon et al., 2002). Mutations in connexin genes are linked to multiple human diseases, including hearing loss, neuropathy, skin and heart diseases (Goodenough et al., 1996; Bone et al., 1997; Denoyelle et al., 1997; Zelante et al., 1997; Simon and Goodenough, 1998; Grifa et al., 1999; Kelsell et al., 2001a, b; Petit et al., 2001; Watts and Chance, 2002).

Mutations in connexin-26 (Cx26), connexin-30 (Cx30), connexin 30.3 (Cx30.3) and connexin-31 (Cx31) are linked to both non-syndromic and syndromic deafness (Denoyelle et al., 1997; Kelsell et al., 1997; Zelante et al., 1997; Xia et al., 1998; Grifa et al., 1999; Lopez-Bigas et al., 2001, 2002b). Electrophysiological studies of Xenopus oocytes expressing different connexin mutants revealed that $\mathrm{HI}$-associated $\mathrm{Cx} 26$ mutants failed to generate intercellular conductance (White et al., 1998; Bruzzone et al., 2001, 2003). Coexpression of wild type and Cx26- or Cx30-disease mutants markedly inhibited the intercellular conductance (White et al., 1998; Grifa et al., 1999; Bruzzone et al., 2001). These findings indicate that the human-disease-linked mutations in connexins impair gap junctional function and may dominantnegatively overwhelm their wild-type counterparts.

"These authors contributed equally to the work. 
Mutations in $\mathrm{C} \times 31$ are identified from patients with $\mathrm{HI}$, erythrokeratodermia variabilis (EKV), and peripheral neuropathy (Richard et al., 1998; Xia et al., 1998; Lopez-Bigas et al., 2001). Interestingly, Cx31 mutants identified from $\mathrm{HI}$ patients and skin-disease patients show exclusive disease phenotypes (Richard et al., 1998; Xia et al., 1998). In addition, disruption of the Cx31 gene results only in transient placental dysmorphogenesis that does not explain its involvement in either HI or skin disease (Dahl et al., 1996; Reuss et al., 1996; Plum et al., 2001). Therefore, deciphering functional mechanisms of Cx31 disease mutations likely yield important information about the roles of Cx31 not only in normal physiological processes but also in initiating pathogenesis of multiple diseases including $\mathrm{HI}$ and skin diseases.

In this study, we showed expression of the $\mathrm{C} \times 31$ protein in the mouse cochlea, a peripheral organ of hearing. Two HIassociated Cx31 mutants, Cx31R180X (C-terminal deletion after amino acid 180 ) and Cx31E183K (E to K substitution at amino acid 183), were neither assembled into gap junctional plaques nor functional in the lucifer dye transfer assay. We further demonstrated that the two $\mathrm{HI}$ mutant proteins were impaired in trafficking and induced ER stress.

\section{RESULTS AND DISCUSSION}

\section{Expression of Cx31 in developing mouse inner ears}

To investigate the involvement of $\mathrm{C} \times 31$ in hearing, we first determined its expression in inner ear, a primary organ of the hearing process. Expression of $\mathrm{C} \times 31$ in inner ear tissues dissected from postnatal day 0 (P0), day 3 (P3), day 6 (P6), day 9 (P9) and adult mice was examined with a Cx31 specific antibody. A strong $\mathrm{C} \times 31$ signal was detected in the spiral ganglion neurons from $\mathrm{P} 0$ to adulthood (Fig. 1, left panel). In the organ of Corti, Cx31 is highly expressed in Hensen's cells from P0 to adult (Fig. 1, right panel). Cx31 was found only at the apical surface of the outer hair cells beginning at $\mathrm{P} 3$ and reached the highest level at P9 (Fig. 1D, F, H, and J). Immunoreactivity in adult outer hair cells appeared to be present throughout the cuticular plate, and not just at the edges where contacts with Deiters' cell processes occur. In inner hair cells, Cx31 was first detected at P3 and reached the highest level of expression in adulthood (Fig. 1D, F, H, and J). Preimmune serum yielded no specific staining of inner ear tissue (not shown).

\section{$\mathrm{HI}$-associated $\mathrm{C} \times 31$ mutant proteins fail to assemble into gap junctional plaques}

We next determined the gap junction formation by $\mathrm{Cx} 31 \mathrm{wt}$ and two Cx31 mutants (E183K and R180X) identified from individuals with high-frequency $\mathrm{HI}$ (Xia et al., 1998). In order to identify exogenously expressed $\mathrm{C} \times 31$ variants, a GFP or a myc-epitope tag was added to the $\mathrm{C}$-termini of the proteins.
GFP- or myc-tagged Cx31 variants were expressed in HeLa cells (Fig. 2A) as well as COS, HEK293, HT1080 and HaCat cells (not shown). Cx31wt and mutant $\mathrm{C} \times 31$ proteins were detected as doublets by immunoblotting (Fig. 2A). The doublets are resistant to phosphotase treatment, likely due to protein degradation (not shown).

Immunofluorescence revealed that both Cx31wtGFP and Cx31wtmyc were assembled into patch-like structures at cellcell contacts (Fig. 2B and $2 \mathrm{C}$ ), indicating that $\mathrm{Cx} 31 \mathrm{wt}$ was assembled effectively into gap junctions. In contrast, no gap junctional plaque-like structures were detected in cells expressing Cx31E183K (including E183KGFP and E183Kmyc) or Cx31R180X (R180XGFP and R180Xmyc). Similar observation was made in both transient transfectants (Fig. 2B) and in stably expressors of the $\mathrm{C} \times 31$ variants (Fig. 2C). Thus, $\mathrm{HI}$-associated $\mathrm{C} \times 31$ mutations fail to assemble into microscopic detectable gap junctions.

To examine whether the $\mathrm{C} \times 31$ mutants can form a microscopic undetectable but functional gap junction, we performed lucifer yellow dye transfer assays. Clusters of HeLa cells expressing GFP-tagged Cx31 variants were identified under fluorescence microscopy. One cell in each cluster was injected with $4 \%$ lucifer yellow. In cells transfected with Cx31wt, lucifer yellow was transferred into adjoining GFP-brightened cells but not to non-GFP-expressing cells within $3 \mathrm{~min}$ after dye injection. In contrast, lucifer yellow transfer was not detected in either Cx31E183K or Cx31R180X transfectants even $20 \mathrm{~min}$ after dye injection. Representative images of the lucifer yellow transfer assay in Cx31 variant transfectants are shown in Fig. 2D. Consistent with a previous report that the hearing loss and neuropathy associated Cx31 D66del does not form channel activity (Di et al., 2002), the $\mathrm{HI}$-associated $\mathrm{Cx} 31$ mutant proteins do not form functional gap junctions. These results suggest that gap junctional activity of $\mathrm{C} \times 31$ likely play important roles in normal hearing.

\section{Differential degradation and subcellular localization of HI-associated Cx31 mutant protein}

To elucidate the molecular mechanism for the inability of Cx31 mutant proteins to assemble into functional gap junction, we examined the half-life of $\mathrm{Cx} 31$ variants expressed in HeLa cells (Fig. 3 ) and COS cells (not shown). The Cx31wt and Cx31E183K proteins exhibited a similar halflife of slightly more than $4 \mathrm{~h}$. The Cx31R180X protein was degraded faster than Cx31wt and Cx31E183K, with a half-life of about $1 \mathrm{~h}$ (Fig. 3B). Similar results were obtained in three independent experiments. Thus, rapid turn-over of the mutant protein may constitute a mechanism for defects in gap junction assembly seen in cells expressing Cx31R180X but not Cx31E183K.

Immunofluorescence revealed Cx31wt at cell-cell contacts and its co-localization with the ER protein calnexin 


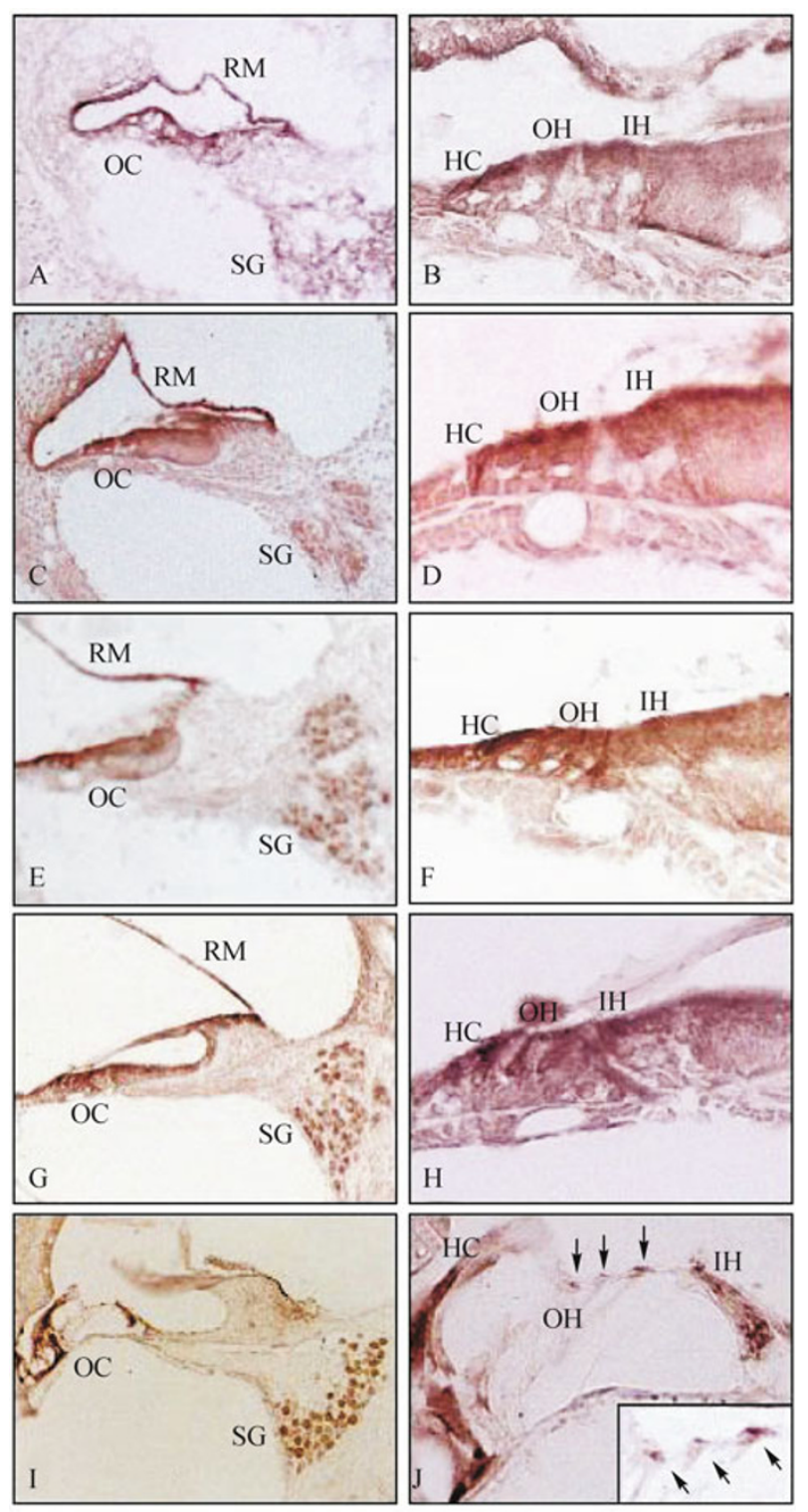

Figure 1. Expression of $\mathbf{C} 31$ in mouse inner ear. Inner ears were dissected from $P 0(A, B), P 3(C, D), P 6(E, F), P 9(G, H)$ and adult $(I, J)$ mice and immunostained with an anti-Cx31 antibody. Representative images of inner ear (left panel, $100 \times$ ) and organ of corti (right panel, $400 \times$ ) are shown. Arrows indicate localization of $\mathrm{Cx} 31$ at tips of adult outer hearing cells $(\mathrm{J})$. Differential expression of $C \times 31$ by Reissner's membrane (RM), organ of corti (OC), spiral ganglion (SG), Hensen's cells (HC), outer hair cells $(\mathrm{OH})$ and inner hair cells $(\mathrm{IH})$ at different stages of inner ears is shown.

(Fig. 4A-C) and the Golgi protein GM130 (Fig. 4J-L). In contrast to $\mathrm{Cx} 31 \mathrm{wt}$, although $\mathrm{C} \times 31 \mathrm{E} 183 \mathrm{~K}$ protein was also detected in Golgi and ER, it was not detected at cell-cell contacts (Fig. 4D-F and 4N-O). In cells expressing lower level of CX31E183K, most of the protein was seen in the Golgi (Fig. 2B). Unlike either Cx31wt or Cx31E183K, Cx31R180X was found primarily in the ER (Fig. 4G-I and 4P-R). Thus, the $\mathrm{C} 31 \mathrm{R} 180 \mathrm{X}$ protein is largely restricted to the early secretory pathway, while the $\mathrm{C} \times 31 \mathrm{E} 183 \mathrm{~K}$ protein is transported to the Golgi and Cx31wt protein is further transported to the late secretory pathway and plasma membrane. The results suggest that $\mathrm{HI}$-associated $\mathrm{C} \times 31$ mutant proteins are defective in intracellular trafficking. The abnormal trafficking of Cx31 mutant proteins likely accounts for the lack of ability of Cx31 mutant proteins to form a functional gap junction.

\section{Correlation between formation of Triton X-100 insoluble Cx31 variants and their intracellular localization}

Previous studies suggest that the assembled connexin- 43 (Cx43) gap junction is Triton X-100 insoluble (Musil and Goodenough, 1991). Triton X-100 insolubility of Cx43 is 

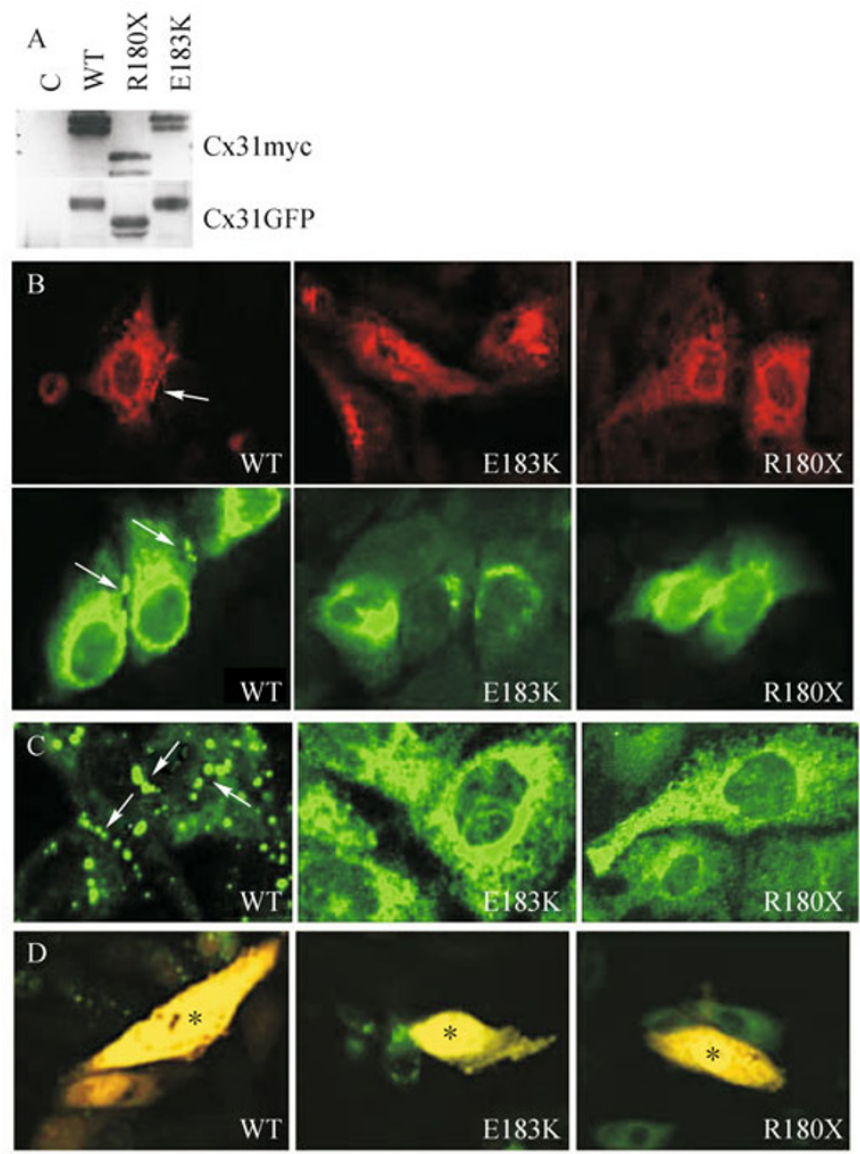

Figure 2. Gap junctional plaque assembly and lucifer yellow transfer of Cx31 variants. HeLa cells were transfected with plasmids encoding myc- or GFP-tagged Cx31wt (WT), Cx31E183K (E183K), or Cx31R180X (R180X). (A) Expression of Cx31 variants. Cell lysates of expressing Cx31 variants tagged with either the myc tag (Cx31myc) or GFP (Cx31GFP) were detected with an anti-myc antibody (upper panel) or an anti-GFP antibody (lower panel). Lysate of cells transfected with empty plasmid served as negative control (C). (B) Localization of Cx31 variants. Cells expressing Cx31myc variants (upper panel) and Cx31GFP variants (lower panel) are shown. Cx31wt (WT) was detected at gap junctional plaques (white arrow). Cx31E183K and Cx31R180X were seen at Golgi and ER-like structures, respectively. (C) Localization of Cx31 in stable transfected Hela cells. Cells stably transfected with Cx31GFP variants (lower panel) are shown. Cx31wt (WT) was detected at gap junctional plaques (white arrow). Intracellular localization of Cx31E183K and Cx31R180X was found. (D) Lucifer yellow transfer of cells expressing Cx31 variants. HeLa cells expressing either GFP-tagged Cx31 variants were examined. One cell in each GFP illuminated cell cluster (indicated by *) was injected with lucifer yellow. Note that lucifer yellow transfer was visualized in cells expressing Cx31wt but not in cells expressing Cx31E183K or Cx31R180X.

correlated more with hemichannel interlocking or cell-cell channel formation than with channel clustering or large connexin plaque formation (Wang et al., 1995). We therefore analyzed whether Cx31 variants formed Triton X-100 insoluble hemichannels in the cell as does $\mathrm{Cx} 43$. As shown in Fig. 5A, Cx31wt and E183K were detected in both soluble and insoluble fractions with an apparent enrichment in the insoluble fractions. However, the Cx31R180X protein was largely present in the soluble fraction with only a small amount present in the insoluble fraction. Higher molecular-weight aggregates were also found in cells expressing $\mathrm{C} \times 31 \mathrm{wt}$ and
Cx31E183K but not in cells expressing Cx31R180X (not shown).

To examine whether the inability of Cx31R180X to form a Triton $X-100$ insoluble complex is due to a lack of an intermolecular interaction that requires the C-terminus, Cx31R180XGFP and Cx31R180Xmyc proteins were coexpressed in cells and analyzed by co-immunoprecipitation. The myc-tagged Cx31R180X was co-immunoprecipitated with GFP-tagged Cx31R180X and vice versa (Fig. 5B). Thus, the intermolecular interaction between Cx31R180X molecules remains intact. Yet, Cx31R180X is incapable of forming 
A

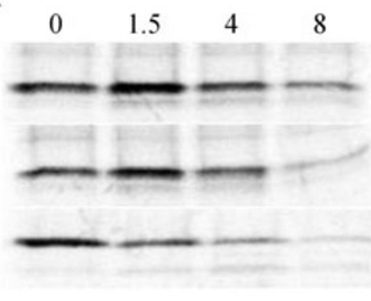

B

WT

E183K

R180X

Figure 3. Stability of Cx31 variants. HeLa cells expressing Cx31 variants, including Cx31wt (WT), Cx31E183K, and Cx31R180X, were pulse labeled with ${ }^{35} \mathrm{~S}$-methionine and chased with unlabeled methionine for periods indicated on the top of the figure. A representative result of the pulse-chase experiments $(A)$ and quantitation of $C \times 31$ variant degradation in three independent experiments (B) are shown. Note that Cx31wt (empty squares) and Cx31E183K (empty circles) have similar degradation kinetics with a half-life of approximately $4 \mathrm{~h}$ while Cx31R180X (empty triangles) has a half-life of around $1 \mathrm{~h}$.
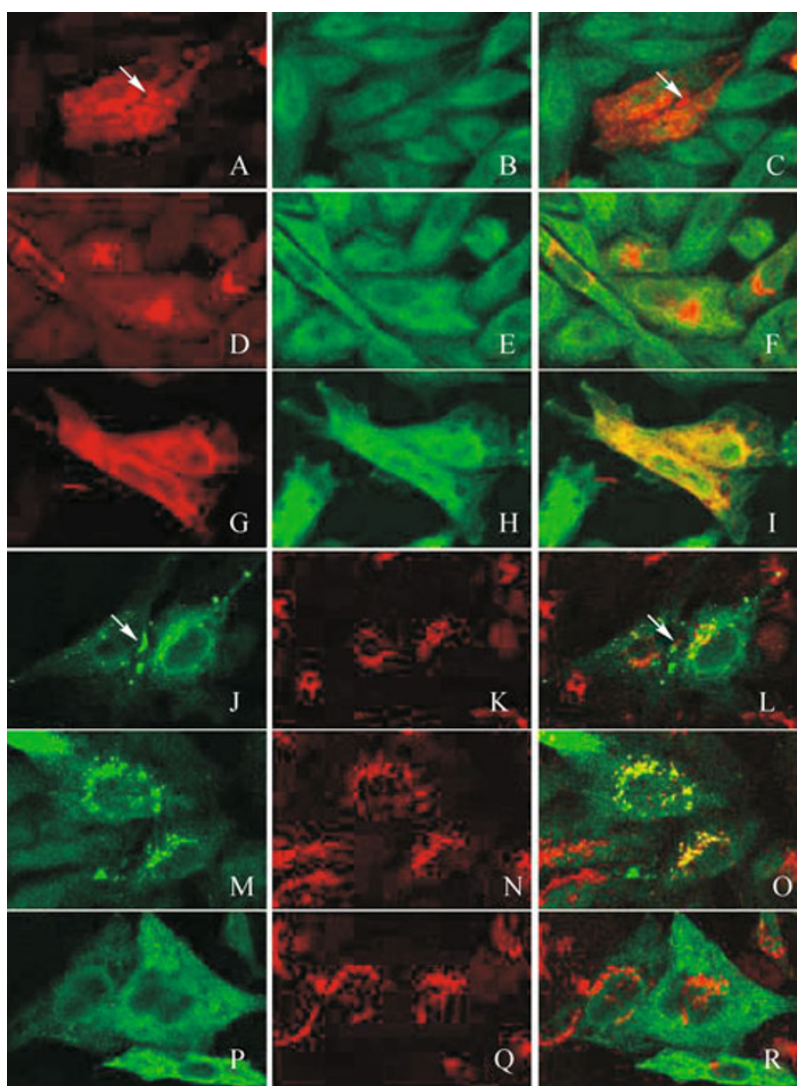

Figure 4. Cellular localization of $\mathbf{C} \times 31$ variants. HeLa cells expressing myc-tagged $\mathrm{C} \times 31 \mathrm{wt}, \mathrm{C} \times 31 \mathrm{E} 183 \mathrm{~K}$, or $\mathrm{C} \times 31 \mathrm{R} 180 \mathrm{X}$ were immunostained with an anti-myc antibody (A, D, G, J, M, P). ER and Golgi were labeled with an anti-calnexin antibody $(B, E, H)$ and an anti-GM130 antibody (K, N, Q), respectively. Colocalization of Cx31 variants and the ER protein calnexin (yellow, C, F, I) was observed in cells expressing all three variants. Colocalization of Cx31 variants with the Golgi protein GM130 was detected in cells expressing Cx31wt (J, K, L) and Cx31E183K (M, N, O), but not in cells expressing Cx31R180X (P, Q, R). Gap junctional plaques are only detected in cells expressing Cx31wt (arrows. A, C, J, L).

Triton $\mathrm{X}-100$ insoluble complexes. The lack of ability of Cx31R180X to form Triton X-100 insoluble complexes may cause a failure in Cx31R180X semi-channel formation. Furthermore, the retention of the Cx31R180X protein in the ER indicates that wild-type $\mathrm{Cx} 31$ semi-channel interlocking occurs in the late secretory pathway.

\section{Induction of BiP expression by $\mathrm{HI}$-associated $\mathrm{Cx} 31$ mutants}

It has been well established that unfolded and misfolded protein will induce cellular stress and abnormal trafficking (Ellgaard et al., 1999). Mutations in plasma membrane 
A

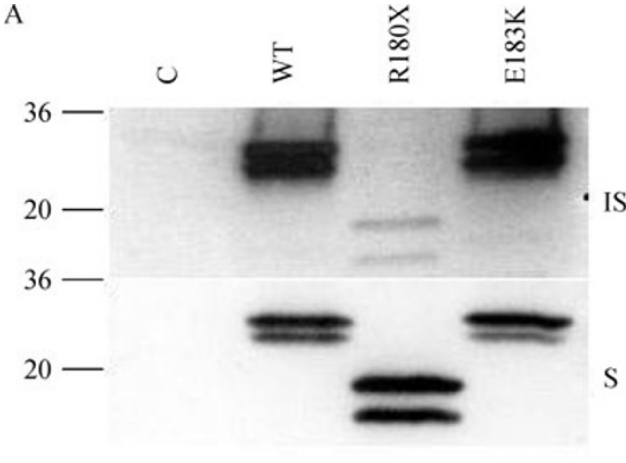

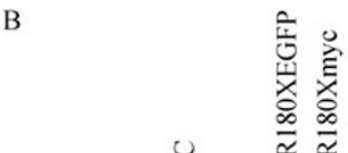

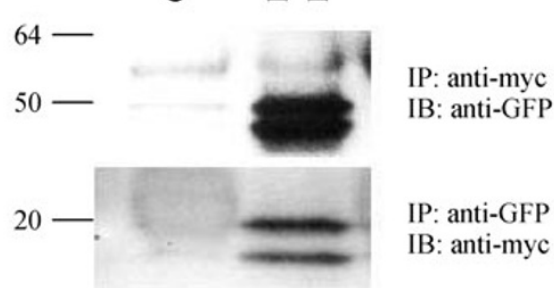

Figure 5. Triton $\mathrm{X}-100$ solubility of $\mathrm{C} \times 31$ variants. (A) Cells were transfected with either a control plasmid $(C)$ or plasmids encoding myc-tagged Cx31 variants (WT, R180X, E183K). Triton X-100 insoluble proteins (IS, upper panel) and soluble proteins ( $\mathrm{S}$, lower panel) were fractionated and immunodetected with an anti-myc antibody. (B) Intermolecular interaction of Cx31R180X protein. Lysates from cells coexpressing Cx31R180XGFP and Cx31R180Xmyc were immunoprecipitated with either an anti-myc antibody (upper panel) or an anti-GFP antibody (lower panel) followed by immunoblotting with an anti-GFP antibody (upper panel) or an anti-myc antibody (lower panel), respectively. As controls (C), cell lysates were precipitated with unrelated mouse IgG (upper panel) or rabbit IgG (lower panel).

proteins lead to either rapid degradation, aggregation, or inhibition of intracellular trafficking of the mutant proteins (Kim and Arvan, 1998; Aridor and Balch, 1999). To explore whether Cx31 mutant proteins are abnormal folded and induce ER stress, we analyzed the expression of the ER chaperone BiP in cells expressing Cx31 variants. Cells expressing Cx31R108X and Cx31E183K showed increased level of BiP detected by immunofluorescence. However, little BiP induction was evidenced in cells expressing $\mathrm{C} \times 31 \mathrm{wt}$ (Fig. 6A). Immunoprecipitation demonstrated a co-precipitation of $\mathrm{C} \times 31$ mutant proteins, but not $\mathrm{C} \times 31 \mathrm{wt}$, with BiP (Fig. 6B). Thus, there is an increased interaction between the ER chaperone BiP and $\mathrm{C} \times 31$ mutant proteins. The results suggest that $\mathrm{HI}$-associated $\mathrm{C} \times 31$ mutants induce $\mathrm{ER}$ stress in the cell.

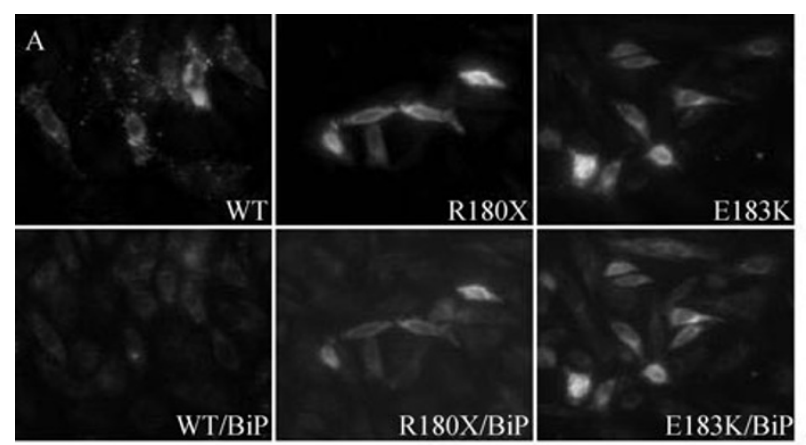

B

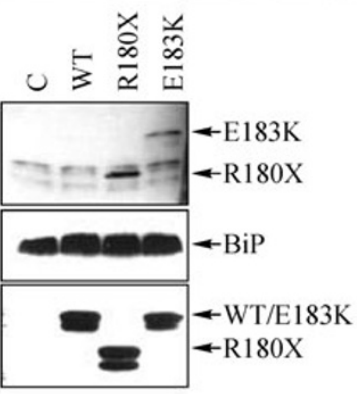

Figure 6. Induction of BiP expression by R180X and E183K. (A) Induction of BiP expression by Cx31 mutants, but not Cx31wt. Hela cells expressing myc-tagged Cx31wt (WT), Cx31R180X and Cx31E183K were immunostained with an anti-myc antibody (upper panel) and an anti-BiP antibody (lower panel), respectively. Note that cells expressing Cx31R180X and Cx31E183K but not Cx31wt were co-labeled with anti-BiP antibody. (B) Co-precipitation of BiP with $\mathrm{C} x 31$ mutant proteins, but not with $\mathrm{C} \times 31$ wt. Cell lysates made from cells transfected with a control plasmid $(C)$, and myc-tagged Cx31wt (WT), Cx31R180X or Cx31E183K were immunoprecipitated with an anti-BiP antibody followed by immunoblotted with an anti-myc antibody (upper panel). Co-precipitation of BiP and Cx31R180X and Cx31E183K, but not Cx31wt (WT) is noted. Expression of $\mathrm{BiP}$ (middle panle) and $\mathrm{C} \times 31$ variants (lower panel) are shown. All corresponding molecules are indicated at the right side of the figure.

\section{DISCUSSION}

We have shown in this study that $\mathrm{HI}$-associated $\mathrm{C} \times 31$ mutant proteins are defective in functional gap junction formation and intracellular trafficking that are likely a consequence of the mutant proteins promoted unfolded protein response (UPR). These cellular abnormalities induced by mutant proteins may contribute to pathogenesis of $\mathrm{C} \times 31$-assocaited hearing impairment.

Expression of endogenous $\mathrm{C} \times 31$ protein in inner hair cells and spiral ganglion neurons strongly supports a function of Cx31 in hearing. It is well recognized that these cells play critical roles in transmitting hearing information into the brain. The observation of the $\mathrm{C} \times 31$ protein in the cuticular plates of outer hair cells, where the cells do not have cell-cell contacts, 
suggest that $\mathrm{C} \times 31$ potentially function as unpaired channels in hair cells (Goodenough and Paul, 2003). A previous study failed to detect $\mathrm{C} \times 31$ transcripts in adult inner hair and outer hair cells using in situ hybridization (Lopez-Bigas et al., 2002a), may have been due to mRNA instability, low rates of transcription while protein half-life is relatively long, or methodological differences between the two studies.

Connexins function as intercellular channels at the cell-cell contact via gap junction formation (Goodenough et al., 1996). The observation that two hearing loss-associated Cx31 mutants fail to be assembled into cell surface semi-channels suggests a loss of function of the mutants. This is consistent with previous reports that $\mathrm{HI}$-associated $\mathrm{C} \times 26$ mutants do not have gap junction activity in Xenopus oocytes (White, 2000). The defect of gap junction formation by $\mathrm{Cx} 31$ disease mutants is likely caused by misfolding of the mutant proteins. These misfolded mutant proteins are either rapid degraded or impaired in trafficking. C-terminal deletion mutant Cx31d179 is largely located at ER while substitution mutant Cx31E183K protein is detected in Golgi. The results indicate that the sorting of $\mathrm{C} \times 31$ mutant proteins is affected by disease mutations. Another critical step for cell to make a functional gap junction is the oligomerization of connexins. Cx31d179 does not form Triton X-100 hexamers while Cx31E183K and Cx31wt do. Since intramolecular interaction of Cx31d179 is not visibly disrupted by the mutation, one possible explanation is that $\mathrm{Cx} 31$ oligomerization occurs in the late secretory pathway. Cx31d179 protein is largely located in ER while Cx31E183K and Cx31wt proteins are transported to Golgi and late secretary pathway. Different connexin may be oligomerized in different organelles (Kumar et al., 1995; VanSlyke et al., 2000; Das Sarma et al., 2001, 2002). Cx32 is likely oligomerized in ER while Cx46 is in Golgi or later secretary pathway (VanSlyke et al., 2000; Das Sarma et al., 2001,2002 ). Our results suggest that $C \times 31$ forms hexamers in Golgi or in the secretary pathway after Golgi.

Finally, binding of unfolded proteins to ER chaperones is a common observation of the primary quality control mechanism that promotes folding and assembly of these proteins. The interaction between ER chaperones and unfolded proteins is also sufficient to cause trafficking alteration of these proteins (Ellgaard et al., 1999; Ellgaard and Helenius, 2001). Our observation suggests that the disease-associated Cx31 mutations may compromise the normal folding and induces the UPR, leading to abnormal trafficking and rapid degradation. Consistent with this notion, Cx31R180X exhibits its primary localization in the ER with a shorter half-life than Cx31wt. It is possible that folding impairment for Cx31E183K is less severe and enable it to escape ER quality control with the help of increased ER chaperones compared to Cx31R180X. Nevertheless, the Cx31E183K protein may be defective in the anterograde transport from the Golgi to the cell surface leading to accumulation in the Golgi, therefore preventing it from reaching the cell surface in sufficient quantity to form a functional gap junction.

\section{MATERIALS AND METHODS}

Cell lines, antibodies, and constructs

Cell lines were purchased from ATCC and cultured under recommended conditions. Antibodies specific for green fluorescent protein (GFP), myc epitope (9E10.2), calnexin, GM-130 were purchased from Clontech, ATCC, Stressgen and Bioscience, respectively. A polyclonal antibody specific for Cx31was generated using a peptide located at amino acid 101-119 (ERRHRQKHGDQCAKLYDNAG) (Abgent). Lucifer yellow was from Molecular Probes. Other reagents were from Sigma. All constructs were made by PCR amplification and verified by sequencing. For amplification, genomic DNA from a normal individual and from individuals harboring the corresponding mutations was used as the template (Xia et al., 1998). Primers (forward: 5'-CGGAATTCTGGGCGCCATGGACTGGAAGACACTCCA-3'; reverse: 5'-GCGTCGACTGGATGGGGGTCAGGTTGGG-3') were used for Cx31wt and Cx31E183K. Primers (forward: 5'-CGGAATTCTGGGCGCCATGGACTGGAAGACACTCCA-3'; reverse: 5'-CCAAGCTTGGGGCAATGTAGCAGTCCACG-3') were used for Cx31R180X. DNAs encoding Cx31 variants were cloned into both $\mathrm{pEGFP/N1}$ (Clontech) and pcDNA3.1(-)MycHisB (Invitrogen) to generate GFP-tagged or myctagged $\mathrm{C} \times 31$ variants, respectively.

\section{Transfection and immuno-assay}

Transfection was performed with Lipofectamine 2000 reagent (Invitrogen) according to the manufacturer's instruction. Stable expressors were selected using G418 followed by ring cloning. Immunofluorescent staining was performed essentially as previously described and analyzed under confocal microscopy (BioRad) (Zhang et al., 1993).

Immunoprecipitation and immunoblotting were done as described (Zhang et al., 1998). Briefly, transfected cells were lysed either in $0.7 \%$ NP-40 buffer (10 mM Hepes, pH7.5, $142.4 \mathrm{mM} \mathrm{KCl,} 5 \mathrm{mM}$ $\mathrm{MgCl}_{2}, 1 \mathrm{mM} \mathrm{EGTA}$, and $0.7 \% \mathrm{NP}-40$ ) or RIPA buffer (Zhang et al., 1998) on ice. Insoluble cellular debris was removed by centrifugation at $14,000 \mathrm{~g}$ at $4^{\circ} \mathrm{C}$ for $30 \mathrm{~min}$. Corresponding antibodies $(3 \mu \mathrm{g})$ and protein $\mathrm{G}$ beads (Roche, $25 \mu \mathrm{L}$ ) were added to cell lysates and incubated at $4^{\circ} \mathrm{C}$ overnight on a nutator. Protein-antibody-bead complexes were washed with corresponding buffer. The proteins were separated on 4\%-20\% Tris-glycine gels (Invitrogen), electrotransferred onto PVDF membranes (Millipore), immunoblotted with indicated antibodies and detected by ECL (Amersham).

Immunohistology of the inner ear: Postnatal day $(P) 0,3,6,9$, and adult mice were fixed via transcardiac perfusion with $4 \%$ paraformaldehyde in $0.1 \mathrm{M}$ phosphate buffer. Adult mouse heads including inner ears were extirpated and decalcified in 8\% EDTA in 4\% paraformaldehyde for 10 days, immersed overnight in $0.1 \mathrm{M}$ phosphate buffer containing $30 \%$ sucrose at $4{ }^{\circ} \mathrm{C}$ and frozen in OCT. Serial sections $(12 \mathrm{~mm})$ were generated on a cryostat and mounted on slides. Masked epitopes were retrieved using $10 \mathrm{mM}$ sodium citrate buffer heated to $95^{\circ} \mathrm{C}$ for $7 \mathrm{~min}$ followed by incubation at room temperature for $20 \mathrm{~min}$, in $0.3 \% \mathrm{H}_{2} \mathrm{O}_{2}$ for $5 \mathrm{~min}$, and $1 \%$ Triton-100/PBS for $20 \mathrm{~min}$. After blocking with $5 \% \mathrm{BSA} / 5 \%$ horse serum in PBS for $1 \mathrm{~h}$, sections were incubated in primary antibody $(1: 250)$ at $4^{\circ} \mathrm{C}$ overnight, washed 3 times with PBS, further incubated in the second antibody (1:500) for $3 \mathrm{~h}$, then developed with DAB solution (Roche). 


\section{Metabolic labeling}

Cells at $90 \%$ confluence were rinsed with methionine-deficient DMEM containing $10 \%$ dialyzed fetal bovine serum (FBS) followed by labeling with the same medium containing ${ }^{35} \mathrm{~S}$-methionine $(150 \mu \mathrm{Ci} /$ $\mathrm{mL}$ ) for $20 \mathrm{~min}$. The cells were then rinsed and chased with normal culture medium containing $450 \mu \mathrm{g} / \mathrm{mL}$ L-methionine. Cx31 variants were immunoprecipitated and analyzed with a phosphorimager.

\section{Triton X-100 solubility analysis of Cx31 variants}

Cells were rinsed once with PBS and incubated on ice for $30 \mathrm{~min}$ in PBS containing $1 \%$ Triton $\mathrm{X}-100$ and protease inhibitor cocktails (Roche). The cells were collected by scraping and further incubated at $4^{\circ} \mathrm{C}$ for $1 \mathrm{~h}$. The samples were then centrifuged at $100,000 \mathrm{~g}$ for $30 \mathrm{~min}$ to separate soluble and insoluble fractions. Both fractions were lysed in SDS sample buffer $(0.5 \mathrm{M}$ Tris HCl, $\mathrm{pH} 6.8,20 \%$ glycerol, $4 \%$ SDS). Equal amounts of protein from each sample were analyzed by immunoblotting.

\section{Dye transfer assay}

HeLa cells were transfected with GFP-tagged Cx31 variants. Lucifer yellow (4\%) was injected into one cell in a cluster of GFP-positive cells using a loose patch clamp whole cell recording technique. Dye transfer was assessed $20 \mathrm{~min}$ after injection using fluorescence microscopy (Nikon). Finally, cells were fixed with $3.7 \%$ paraformaldehyde. Images were captured using confocal microscopy.

\section{ACKNOWLEDGEMENTS}

This work was supported by grants from the Chinese National Science Foundation (ZZ, KX, DLW) and the NIH/NIDCD (ZZ).

\section{ABBREVIATIONS}

Cx26, connexin-26; Cx30, connexin-30; Cx30.3, connexin 30.3; Cx31, connexin-31; Cx31wt, wild type Cx31 protein; FBS, fetal bovine serum; GFP, green fluorescent protein; $\mathrm{HI}$, hearing impairment

\section{REFERENCES}

Aridor, M., and Balch, W.E. (1999). Integration of endoplasmic reticulum signaling in health and disease. Nat Med 5, 745-751.

Bone, L.J., Deschenes, S.M., Balice-Gordon, R.J., Fischbeck, K.H., and Scherer, S.S. (1997). Connexin32 and X-linked CharcotMarie-Tooth disease. Neurobiol Dis 4, 221-230.

Bruzzone, R., Gomes, D., Denoyelle, E., Duval, N., Perea, J., Veronesi, V., Weil, D., Petit, C., Gabellec, M.M., D'Andrea, P., et al. (2001). Functional analysis of a dominant mutation of human connexin26 associated with nonsyndromic deafness. Cell Commun Adhes 8, 425-431.

Bruzzone, R., Veronesi, V., Gomes, D., Bicego, M., Duval, N., Marlin, S., Petit, C., D'Andrea, P., and White, T.W. (2003). Loss-of-function and residual channel activity of connexin26 mutations associated with non-syndromic deafness. FEBS Lett 533, 79-88.

Cohen-Salmon, M., Ott, T., Michel, V., Hardelin, J.P., Perfettini, I., Eybalin, M., Wu, T., Marcus, D.C., Wangemann, P., Willecke, K., et al. (2002). Targeted ablation of connexin26 in the inner ear epithelial gap junction network causes hearing impairment and cell death. Curr Biol 12, 1106-1111.

Dahl, E., Manthey, D., Chen, Y., Schwarz, H.J., Chang, Y.S., Lalley, P. A., Nicholson, B.J., and Willecke, K. (1996). Molecular cloning and functional expression of mouse connexin-30,a gap junction gene highly expressed in adult brain and skin. J Biol Chem 271, 17903-17910.

Das Sarma, J., Meyer, R.A., Wang, F., Abraham, V., Lo, C.W., and Koval, M. (2001). Multimeric connexin interactions prior to the trans-Golgi network. J Cell Sci 114, 4013-4024.

Das Sarma, J., Wang, F., and Koval, M. (2002). Targeted gap junction protein constructs reveal connexin-specific differences in oligomerization. J Biol Chem 277, 20911-20918.

Denoyelle, F., Weil, D., Maw, M.A., Wilcox, S.A., Lench, N.J., AllenPowell, D.R., Osborn, A.H., Dahl, H.H., Middleton, A., Houseman, M.J., et al. (1997). Prelingual deafness: high prevalence of a 30 delG mutation in the connexin 26 gene. Hum Mol Genet 6, 2173-2177.

Di, W.L., Monypenny, J., Common, J.E., Kennedy, C.T., Holland, K.A., Leigh, I.M., Rugg, E.L., Zicha, D., and Kelsell, D.P. (2002). Defective trafficking and cell death is characteristic of skin disease-associated connexin 31 mutations. Hum Mol Genet 11, 2005-2014.

Elfgang, C., Eckert, R., Lichtenberg-Frate, H., Butterweck, A., Traub, O., Klein, R.A., Hulser, D.F., and Willecke, K. (1995). Specific permeability and selective formation of gap junction channels in connexin-transfected HeLa cells. J Cell Biol 129, 805-817.

Ellgaard, L., and Helenius, A. (2001). ER quality control: towards an understanding at the molecular level. Curr Opin Cell Biol 13, 431-437.

Ellgaard, L., Molinari, M., and Helenius, A. (1999). Setting the standards: quality control in the secretory pathway. Science 286 , 1882-1888.

Goodenough, D.A., Goliger, J.A., and Paul, D.L. (1996). Connexins, connexons, and intercellular communication. Annu Rev Biochem $65,475-502$.

Goodenough, D.A., and Paul, D.L. (2003). Beyond the gap: functions of unpaired connexon channels. Nat Rev Mol Cell Biol 4, 285-294.

Grifa, A., Wagner, C.A., D'Ambrosio, L., Melchionda, S., Bernardi, F., Lopez-Bigas, N., Rabionet, R., Arbones, M., Monica, M.D., Estivill, X., et al. (1999). Mutations in GJB6 cause nonsyndromic autosomal dominant deafness at DFNA3 locus. Nat Genet 23, 16-18.

Kelsell, D.P., Di, W.L., and Houseman, M.J. (2001a). Connexin mutations in skin disease and hearing loss. Am J Hum Genet 68, 559-568.

Kelsell, D.P., Dunlop, J., and Hodgins, M.B. (2001b). Human diseases: clues to cracking the connexin code? Trends Cell Biol 11, 2-6.

Kelsell, D.P., Dunlop, J., Stevens, H.P., Lench, N.J., Liang, J.N., Parry, G., Mueller, R.F., and Leigh, I.M. (1997). Connexin 26 mutations in hereditary non-syndromic sensorineural deafness. Nature 387, 80-83.

Kim, P.S., and Arvan, P. (1998). Endocrinopathies in the family of endoplasmic reticulum (ER) storage diseases: disorders of protein trafficking and the role of ER molecular chaperones. Endocr Rev 19, 173-202.

Kumar, N.M., Friend, D.S., and Gilula, N.B. (1995). Synthesis and assembly of human beta 1 gap junctions in BHK cells by DNA 
transfection with the human beta 1 cDNA. J Cell Sci 108 (Pt 12), 3725-3734.

Lopez-Bigas, N., Arbones, M.L., Estivill, X., and Simonneau, L. (2002a). Expression profiles of the connexin genes, Gjb1 and Gjb3, in the developing mouse cochlea. Mech Dev 119 Suppl 1, S111-115.

Lopez-Bigas, N., Melchionda, S., Gasparini, P., Borragan, A., Arbones, M.L., and Estivill, X. (2002b). A common frameshift mutation and other variants in GJB4 (connexin 30.3): Analysis of hearing impairment families. Hum Mutat 19, 458.

Lopez-Bigas, N., Olive, M., Rabionet, R., Ben-David, O., MartinezMatos, J.A., Bravo, O., Banchs, I., Volpini, V., Gasparini, P., Avraham, K.B., et al. (2001). Connexin 31 (GJB3) is expressed in the peripheral and auditory nerves and causes neuropathy and hearing impairment. Hum Mol Genet 10, 947-952.

Musil, L.S., and Goodenough, D.A. (1991). Biochemical analysis of connexin43 intracellular transport, phosphorylation, and assembly into gap junctional plaques. J Cell Biol 115, 1357-1374.

Petit, C., Levilliers, J., and Hardelin, J.P. (2001). Molecular genetics of hearing loss. Annu Rev Genet 35, 589-646.

Plum, A., Winterhager, E., Pesch, J., Lautermann, J., Hallas, G., Rosentreter, B., Traub, O., Herberhold, C., and Willecke, K. (2001). Connexin31-deficiency in mice causes transient placental dysmorphogenesis but does not impair hearing and skin differentiation. Dev Biol 231, 334-347.

Reuss, B., Hellmann, P., Dahl, E., Traub, O., Butterweck, A., Grummer, R., and Winterhager, E. (1996). Connexins and Ecadherin are differentially expressed during trophoblast invasion and placenta differentiation in the rat. Dev Dyn 205, 172-182.

Richard, G., Smith, L.E., Bailey, R.A., Itin, P., Hohl, D., Epstein, E.H., Jr., DiGiovanna, J.J., Compton, J.G., and Bale, S.J. (1998). Mutations in the human connexin gene GJB3 cause erythrokeratodermia variabilis. Nat Genet 20, 366-369.

Simon, A.M., and Goodenough, D.A. (1998). Diverse functions of vertebrate gap junctions. Trends Cell Biol 8, 477-483.

VanSlyke, J.K., Deschenes, S.M., and Musil, L.S. (2000). Intracellular transport, assembly, and degradation of wild-type and diseaselinked mutant gap junction proteins. Mol Biol Cell 11, 1933-1946.

Wang, Y., Mehta, P.P., and Rose, B. (1995). Inhibition of glycosylation induces formation of open connexin-43 cell-to-cell channels and phosphorylation and triton X-100 insolubility of connexin-43. J Biol Chem 270, 26581-26585.

Watts, G.D., and Chance, P.F. (2002). Molecular basis of hereditary neuropathies. Adv Neurol 88, 133-146.

White, T.W. (2000). Functional analysis of human Cx26 mutations associated with deafness. Brain Res Brain Res Rev 32, 181-183.

White, T.W., Deans, M.R., Kelsell, D.P., and Paul, D.L. (1998). Connexin mutations in deafness. Nature 394, 630-631.

Xia, J.H., Liu, C.Y., Tang, B.S., Pan, Q., Huang, L., Dai, H.P., Zhang, B.R., Xie, W., Hu, D.X., Zheng, D., et al. (1998). Mutations in the gene encoding gap junction protein beta-3 associated with autosomal dominant hearing impairment. Nat Genet 20, 370-373.

Zelante, L., Gasparini, P., Estivill, X., Melchionda, S., D'Agruma, L., Govea, N., Mila, M., Monica, M.D., Lutfi, J., Shohat, M., et al. (1997). Connexin26 mutations associated with the most common form of non-syndromic neurosensory autosomal recessive deafness (DFNB1) in Mediterraneans. Hum Mol Genet 6, 1605-1609.

Zhang, Z., Hartmann, H., Do, V.M., Abramowski, D., Sturchler-Pierrat, C., Staufenbiel, M., Sommer, B., van de Wetering, M., Clevers, H., Saftig, P., et al. (1998). Destabilization of beta-catenin by mutations in presenilin-1 potentiates neuronal apoptosis. Nature 395 , 698-702.

Zhang, Z., Morla, A.O., Vuori, K., Bauer, J.S., Juliano, R.L., and Ruoslahti, E. (1993). The alpha $v$ beta 1 integrin functions as a fibronectin receptor but does not support fibronectin matrix assembly and cell migration on fibronectin. J Cell Biol 122, 235-242. 